\title{
Produção de melão Pele de Sapo híbrido 'Medellín' cultivado com diferentes salinidades da água ${ }^{1}$
}

\author{
Production of the hybrid Pele-de-Sapo melon Medellín cultivated at different water \\ salinities
}

\author{
Damiana Cleuma de Medeiros ${ }^{2}$, José Francismar de Medeiros ${ }^{3}$, Pollyana Mona Soares Dias ${ }^{4}$, Murillo Anderson \\ Gonçalves Barbosa ${ }^{5 *}$ e Keivianne da Silva Lima ${ }^{4}$
}

\begin{abstract}
Resumo - Dentre os problemas enfrentados pela cultura do melão no Estado do Rio Grande do Norte, a salinidade da água e do solo é um dos principais fatores limitantes da produção e da qualidade dos frutos. O objetivou-se com este trabalho estudar os efeitos de aplicação de águas de irrigação com diferentes níveis de salinidade na produção de melão Pele de Sapo híbrido 'Medellín'. O delineamento utilizado foi o de blocos inteiramente casualizados com quatro repetições. Os tratamentos constaram de concentrações de sais na água de irrigação $(0,54 ; 1,48 ; 2,02 ; 3,03$ e $\left.3,9 \mathrm{dS} \mathrm{m}^{-1}\right)$. As características de produção avaliadas foram: produtividade comercial e produtividade total, número de frutos comerciais por planta, número de frutos totais, massa média de frutos comerciais, massa média dos frutos totais. $\mathrm{O}$ incremento da salinidade na água influenciou negativamente o rendimento da cultura, com perdas relativas por incremento unitário de salinidade acima de $0,54 \mathrm{dS} \mathrm{m}^{-1}$, de 7,5\%; 7,8\%; 8,32\% e 8,70\%, para produtividade comercial e total e número de frutos comerciais e totais, respectivamente.
\end{abstract}

Palavras-chave - Cucumis melo L. Qualidade da água. Condutividade Elétrica.

\begin{abstract}
Among the problems facing cultivation of the melon in the State of Rio Grande do Norte, the salinity of the water and soil is a major limiting factor of both production and fruit quality. The objective of this work was to study the effects on the production of the hybrid Pele-de-Sapo melon Medellin, of irrigation waters at different salinity levels. The experimental design was a completely randomized block with four replications, with treatments consisting of different salt-concentrations in the irrigation water $\left(0.54 ; 1.48 ; 2.02 ; 3.03\right.$ and $\left.3.9 \mathrm{dS} \mathrm{m}^{-1}\right)$. The production features measured were: total yield and commercial yield; total number of marketable fruits per plant; total number of fruits; mean weight of the marketable fruits, and total mean weight of the fruits. The increase in water salinity negatively affected the crop yield, with relative losses per unit increase in salinity of above $0.54 \mathrm{dS} \mathrm{m}^{-1}, 7.5 \% ; 7.8 \% ; 8.32 \%$ and $8.70 \%$ for commercial and total production, and the number of marketable fruits and total fruits, respectively.
\end{abstract}

Key words - Cucumis melo L. Water quality. Electrical conductivity.

\footnotetext{
* Autor para correspondência

Recebido para publicação em 31/08/2010; aprovado em 31/01/2011

Trabalho submetido e selecionado no primeiro Simposio Brasileiro de Salinidade realizado de 12-15/10/2010 em Fortaleza, Ceará, Brasil

${ }^{2}$ Departamento do Agronomia/Fitotecnia/UFERSA, Mossoró-RN, Brasil, damianacm@hotmail.com

${ }_{3}^{3}$ Departamento de Ciências Ambientais/UFERSA, Mossoró-RN, Brasil, jfmedeir@ufersa.edu.br

${ }^{4}$ Universidade Federal Rural do Semi-Árido, Mossoró-RN, Brasil, monadias06@hotmail.com, kei.v@hotmail.com

${ }^{5}$ Departamento de Ciências Ambientais/UFERSA, Caixa Postal 137, Mossoró, RN, Brasil, 59.625-900, Fone (84) 9654.6856, murilloanderson@ hotmail.com
} 


\section{Introdução}

No Brasil, no ano de 2007, foram produzidos $500.021 \mathrm{t}$ de melões em 21.350 ha de área colhida, sendo a região nordeste responsável por $86 \%$ da área colhida e produção, respectivamente (IBGE, 2008). A produção de melão no estado do Rio Grande do Norte se concentra no pólo agrícola Mossoró-Açu e na Chapada do Apodi, englobando a região semi árida, próxima à zona litorânea, na qual se baseia na irrigação feita com água bombeada dos poços tubulares que exploram o aqüífero Cálcario Jandaíra, cujas águas podem apresentar condutividades elétricas superiores a 3,0 dS m ${ }^{-1}$. Nessas áreas, a intensa evapotranspiração, o uso de água salobra e o próprio uso de fertilizantes, têm aumentado os problemas com a salinidade, prejudicando o rendimento das culturas (MEDEIROS et al., 2003).

Os efeitos dos sais sobre as plantas podem ser notados pelas dificuldades de absorção de água salina, pela interferência dos sais nos processos fisiológicos, ou mesmo por toxidez, similares àquelas de adubações excessivas (QUEIROGA et al., 2006). Dentre os problemas enfrentados pela cultura, a salinidade da água e do solo são fatores limitantes a uma boa produção e qualidade dos frutos. O meloeiro apresenta grande variação no nível de tolerância à salinidade, variando tanto entre cultivares quanto em relação às condições ambientais e de manejo (FRANCOIS; MAAS, 1993).

Alencar et al. (2003) observaram que frente à resposta das cultivares de melão em relação à salinidade da água de irrigação, não houve efeito significativo entre as mesmas para os parâmetros altura de plantas, área foliar, fitomassa da parte aérea fresca e seca, em todas as avaliações, exceto para 32 dias após semeadura (DAS).

Silva et al. (2005), estudando a produtividade de frutos do meloeiro sob diferentes níveis de salinidade da água de irrigação mostraram que a produtividade total sofreu redução com o aumento do nível de salinidade da água, o que é comum para quase todas as culturas.

Para Sivitrepe et al. (2003), as elevadas concentrações de sais no solo e na água ocasionam modificações morfológicas, estruturais e metabólicas em plântulas de melão, inibem o seu crescimento e desenvolvimento, reduzindo a porcentagem de massa seca nas plantas, no tamanho dos frutos e rendimento.

Dias et al. (2003) afirmam que a tolerância da cultura varia tanto entre espécie de plantas como para cultivares da mesma espécie. O meloeiro apresenta tolerância moderada à concentração de sais na solução do solo. Irrigação com água de salinidade alta (até $2,5 \mathrm{dS} \mathrm{m}^{-1}$ ), desde que bem manejada e em solo com boa drenagem, pode produzir frutos mais doces, com alto teor de sólidos solúveis e sem produzir reduções significativas na produtividade (CUENCA, 1989). Todavia, durante a fase de crescimento inicial, a planta é mais sensível à salinidade e parece que salinidade elevada do solo durante o período de floração pode reduzir o número de frutos pegados (CUENCA, 1989).

Há a necessidade de desenvolver cultivares de melão com tolerância a sais, devido ao aumento da salinidade nos solos (SIVITREPE et al., 2003).

Em nossas condições onde há um aumento constante da salinidade dos solos devido às águas usadas na irrigação, necessita-se de cultivares de melão que possam produzir com viabilidade econômica suprindo demanda do produto. Assim, o objetivo do experimento foi avaliar a produção de melão tipo Pele de Sapo híbrido 'Medellín', quando submetidos à irrigação com diferentes níveis de salinidade.

\section{Material e métodos}

O experimento foi conduzido na fazenda Pedra Preta situada as margens direita da BR $304 \mathrm{RN}$ no Km 13, localizada no município de Mossoró, Rio Grande do Norte, com coordenadas geográficas 4³9'39” S, 37²3'13" W e $34 \mathrm{~m}$ de altitude e clima BSwh' segundo classificação de Köppen. De acordo com Carmo Filho et al. (1991) as características climáticas do município são: temperatura média de $27,4{ }^{\circ} \mathrm{C}$, a precipitação pluviométrica média de $673,9 \mathrm{~mm}$, e umidade relativa média de $68,9 \%$. Durante o cultivo, o comportamento do tempo foi similar a média climatológica, chovendo no período apenas $15 \mathrm{~mm}$ no final do cultivo.

O solo utilizado no experimento é classificado como Argissolo Amarelo (EMBRAPA, 1999). O preparo do solo foi feito trinta dias antes do transplantio, utilizando uma gradagem, subsolagem, abertura dos sulcos e levantamento dos camalhões. Foram coletadas amostras de solo antes do preparo e avaliadas as características químicas e físicas. Estas análises foram realizadas no Laboratório de Irrigação e Salinidade do Departamento de Ciências Ambientais da Universidade Federal Rural do Semi-árido - UFERSA e no Laboratório de Engenharia Agrícola da Universidade Federal de Campina Grande UFCG. Nas Tabelas 1 e 2 estão os resultados as análises químicas e físico-hídricas de solo.

As plantas foram adubadas com $420 \mathrm{~kg} \mathrm{ha}^{-1}$ da formulação comercial 6-24-12, o que equivale à aplicação de $25,2 \mathrm{~kg} \mathrm{ha}^{-1}$ de $\mathrm{N}, 100,8 \mathrm{~kg} \mathrm{ha}^{-1}$ de $\mathrm{P}_{2} \mathrm{O}_{5}$ e de $50,4 \mathrm{~kg} \mathrm{ha}^{-1}$ de $\mathrm{K}_{2} \mathrm{O}$. Já as adubações de cobertura foram feitas via fertirrigação, baseados em análise de solo e nas recomendações de Crisóstomo et al. (2002), sendo que no ciclo, aplicou-se as seguintes quantidades de 
Tabela 1 - Caracterização química do solo da área experimental

\begin{tabular}{|c|c|c|c|c|c|c|c|c|c|}
\hline Camada & $\mathrm{pH}$ & MO & $\mathrm{P}$ & $\mathrm{K}^{+}$ & $\mathrm{Mg}^{+}$ & $\mathrm{Ca}^{2+}$ & $\mathrm{Mg}^{2+}$ & $\mathrm{H}^{+} \mathrm{Al}^{3+}$ & CTC \\
\hline $\mathrm{cm}$ & água & $\mathrm{g} \mathrm{kg}^{-1}$ & $\mathrm{mg} \mathrm{dm}^{-3}$ & & 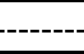 & $-\mathrm{mm}$ & $n^{-3}--$ & --------- & -- \\
\hline $0-20$ & 8,0 & 3,0 & 10,0 & 1,1 & 9,0 & 9,0 & 4,0 & 18,0 & 32,1 \\
\hline $20-40$ & 8,0 & 3,0 & 10,0 & 1,1 & 9,0 & 9,0 & 4,0 & 18,0 & 32,1 \\
\hline
\end{tabular}

Tabela 2 - Caracterização físico-hídrica do solo da área experimental

\begin{tabular}{|c|c|c|c|c|c|c|c|c|}
\hline \multirow{2}{*}{ Camada } & \multirow{2}{*}{$\mathrm{CC}$} & \multirow{2}{*}{ PMP } & \multirow{2}{*}{$\mathrm{Dg}$} & \multicolumn{3}{|c|}{ Frações granulométricas } & \multirow{2}{*}{ Floculação } & \multirow{2}{*}{ Textura } \\
\hline & & & & Argila & Silte & Areia & & \\
\hline $\mathrm{cm}$ & ------ $\mathrm{cn}$ & $1^{-3}--------$ & $\mathrm{kg} \mathrm{dm}^{-3}$ & - ----- & $\mathrm{g} \mathrm{kg}^{-1}$ & ----- & $\%$ & \\
\hline $0-20$ & 0,222 & 0,111 & 1,450 & 200 & 100 & 700 & 100 & Arenosa \\
\hline
\end{tabular}

nutrientes: $81 \mathrm{~kg} \mathrm{ha}^{-1}$ de $\mathrm{N}, 93 \mathrm{~kg} \mathrm{ha}^{-1}$ de $\mathrm{P}_{2} \mathrm{O}_{5}$ e $188 \mathrm{~kg} \mathrm{ha}^{-1}$ de $\mathrm{K}_{2} \mathrm{O}$. Complementarmente a aplicação de fertilizantes com micronutrientes de acordo com a fase e a exigência nutricional e também via foliar foi aplicado $6,83 \mathrm{~L} \mathrm{ha}^{-1} \mathrm{de}$ $\mathrm{CaB}_{2}, 2,46 \mathrm{~L} \mathrm{ha}^{-1}$ de Máster Frutis e 1,09 $\mathrm{L} \mathrm{ha}^{-1}$ de Megafor. Os principais adubos utilizados na fertirrigação foram: Uréia, ácido nítrico, fosfato monoamônico (MAP), acido fosfórico, nitrato de potássio, nitrato de cálcio e sulfato de magnésio. A solução com fertilizante era preparada sempre com a água de menor salinidade, logo em seguida colocada em um tanque de derivação com capacidade de 15 litros, injetado na rede antes do cabeçal de controle. Quando existia incompatibilidade entre os adubos eram utilizadas duas fertirrigações diárias, uma pela manhã e outra à tarde conforme a necessidade de irrigação.

Foi utilizado para cobertura dos camalhões filme de polietileno (mulching) com faces preta-branca durante todo o ciclo, e até o inicio da floração as plantas foram protegidas com manta agrotextil (TNT). A irrigação das parcelas foi feita pelo sistema de gotejamento com emissores espaçados $0,30 \mathrm{~m}$ e vazão de $1,35 \mathrm{~L} \mathrm{~h}^{-1}$. Durante todo o ciclo foi aplicado uma lâmina total $324 \mathrm{~mm}$. Foram realizadas práticas culturais como capinas e pulverizações de acordo com as necessidades.
A área do experimento foi composta por oito blocos de $20 \mathrm{~m}$ de largura por $30 \mathrm{~m}$ de comprimento com quatro repetições, totalizando uma área útil total de 0,48 ha. Essa área foi abastecida por duas fontes de água, uma de origem calcária, de baixa qualidade, extraída do sedimento calcário através de poços tubulares com média de $100 \mathrm{~m}$ de profundidade. A outra fonte de água é originaria do arenito Açu, que neste ponto está localizado a aproximadamente $1000 \mathrm{~m}$ de profundidade, sendo sua água considerada de excelente qualidade. Na Tabela 3 estão os dados das análises químicas das duas fontes de água.

O melão utilizado foi o tipo Pele de Sapo, híbrido "Medellín”, caracterizado por apresentar frutos graúdos, de ótima conservação pós-colheita e qualidade (firmeza e Brix) atendendo às exigências do mercado de exportação e doméstico. Apresenta ciclo tardio, vigor bom, formato oval, tamanho grande e ótima conservação pós-colheita.

O delineamento utilizado foi inteiramente casualizado com quatro repetições. Os tratamentos constaram de concentrações de sais na água de irrigação que equivale às seguintes condutividades elétricas - $\mathrm{CE}$ $\left(0,54 ; 1,48 ; 2,02 ; 3,03\right.$ e $\left.3,90 \mathrm{dS} \mathrm{m}^{-1}\right)$. A CE foi obtida mediante a mistura das águas das duas fontes. A água foi aplicada por um sistema independente com uma linha

Tabela 3 - Análise química das águas utilizada no experimento

\begin{tabular}{cccccccccc}
\hline Água & $\mathrm{CE}$ & $\mathrm{pH}$ & $\mathrm{Ca}^{2+}$ & $\mathrm{Mg}^{+}$ & $\mathrm{K}^{+}$ & $\mathrm{Na}^{+}$ & $\mathrm{Cl}^{-}$ & $\mathrm{HCO}_{3}^{-}$ & $\mathrm{CO}_{3}^{-2}$ \\
\hline Fonte & $\mathrm{dS} \mathrm{m}{ }^{-1}$ & Água & ------------------------ & $\mathrm{mmol}_{\mathrm{c}} \mathrm{dm}^{-3}$--------------------- & \\
\hline Açu & 0,54 & 7,15 & 1,80 & 0,50 & 0,53 & 0,79 & 1,60 & 4,10 & 0,35 \\
Jandaira & 3,90 & 6,90 & 15,2 & 2,80 & 0,15 & 19,00 & 25,20 & 4,80 & 0,20 \\
\hline
\end{tabular}

* Análise qualitativa 
lateral por fileira de planta. A semeadura foi realizada no segundo semestre de 2008, em bandejas de poliestireno de 128 células preenchidas com substrato agrícola comercial. O transplantio foi realizado aos 12 dias após a semeadura quando a segunda folha apresentava-se completamente expandida. Cada parcela foi formada por quatro fileiras de $6 \mathrm{~m}$ de comprimento e espaçadas de $2 \mathrm{~m}$, sendo as duas fileiras centrais consideradas como área útil da parcela. $\mathrm{O}$ espaçamento entre plantas foi de $0,4 \mathrm{~m}$ nas linhas, totalizando 15 plantas em cada fileira, das quais foram ainda eliminadas duas plantas de cada extremidade da linha, consideradas bordaduras, ficando assim 11 plantas úteis por fileira e 22 foram considerada para medição da produção. produção:

Avaliaram-se as seguintes características de

a) Produtividade de frutos comerciais (PRC) e totais (PRT): foi obtido dividindo o soma das massas dos frutos aptos à exportação, pelo número de plantas colhidas na parcela útil e posteriormente multiplicado pelo número de plantas em 1 ha e a produtividade total de frutos (PRT): foi calculado somando as massa dos frutos aptos a comercialização, tanto para o mercado exportação quando para o mercado interno, dividindo esse valor pelo número de plantas colhidas na parcela útil e multiplicado pelo número de plantas em um hectare.

b) Número de frutos comerciais (NFC) e totais (NFT): foi obtido a partir do número de frutos totais aptos à exportação por parcela, dividido pelo número de plantas úteis colhidas. O NFT obtido a partir do número total de frutos aptos à comercialização externa e interna em cada parcela, dividido pelo número de plantas colhidas na parcela útil. c) Massa média de frutos comerciais (MMFC) e totais (MMFT): A MMFT foi obtida a partir da massa total de frutos aptos à exportação, dividido pelo número de frutos das plantas colhidas na parcela útil. A MMFT foi obtida a partir do peso total de frutos aptos à comercialização externa e interna, dividido pelo numero de plantas colhidas na parcela útil.

Os valores relativos foram calculados em relação ao menor valor absoluto da menor condutividade elétrica.

As análises de variância e de regressão das características avaliadas foram realizadas utilizandose o programa SAEG v. 9.0 (RIBEIRO JÚNIOR, 2001) Selecionou-se os modelos de regressão com base no significado biológico, na significância dos coeficientes de regressão, ao nível de $5 \%$ de significância, pelo teste $\mathrm{F}$, e no maior coeficiente de determinação $\left(\mathrm{R}^{2}\right)$.

\section{Resultados e discussão}

Observa-se na Tabela 4 da análise de variância que houve efeito significativo dos níveis de salinidade para as características produtividade de frutos totais e número de frutos comerciais e totais para valores absolutos e relativos, indicando um modelo linear que decresce com o aumento dos valores de condutividade elétrica da água de irrigação, na qual pode ser adotado para explicar as características de produção. Medeiros et al. (2007) e Silva et al. (2005) encontraram comportamentos semelhantes. Em relação às características produtividade de frutos comerciais, massa média de frutos comerciais e totais não houve efeito nem do componente linear e nem do quadrático do fator salinidade (TAB. 4).

Tabela 4 - Resumo da análise de variância produtividade de frutos comerciais (PFC) e totais (PFT), número de frutos comerciais (NFC) e totais (NFT), massa média de frutos comerciais (MMFC) e totais (MMFT) de melão Pele de Sapo híbrido 'Medellín' em função de diferentes níveis de salinidade

\begin{tabular}{cccccccc}
\hline \multirow{2}{*}{ FV } & GL & PRC & PRT & NFC & NFT & MMFC & MMFT \\
\cline { 2 - 8 } & & \multicolumn{7}{c}{ Estatística F } \\
\hline CE & 4 & $2,832^{\text {ns }}$ & $3,583^{*}$ & $3,209^{*}$ & $4,082^{*}$ & $0,330^{\text {ns }}$ & $0,464^{\text {ns }}$ \\
Linear & 1 & $8,81^{*}$ & $13,7^{* *}$ & $10,57^{* *}$ & $15,18^{* *}$ & $0,76^{\text {ns }}$ & $1,7^{\text {ns }}$ \\
Quadrático & 1 & $0,61^{\text {ns }}$ & $0,54^{\text {ns }}$ & $0,58^{\text {ns }}$ & $0,86^{\text {ns }}$ & $0,08^{\text {ns }}$ & $0,08^{\text {ns }}$ \\
Bloco & 3 & $0,093^{\text {ns }}$ & $0,262^{\text {ns }}$ & $0,229^{\text {ns }}$ & $0,598^{\text {ns }}$ & $1,011^{\text {ns }}$ & $0,871^{\text {ns }}$ \\
Erro & 12 & & & & & & \\
\hline CV $(\%)$ & & 15,25 & 13,03 & 15,70 & 14,08 & 5,64 & 5,64 \\
\hline Média Geral & & 41,808 & 50,117 & 1,114 & 1,407 & 3,005 & 2,857 \\
\hline
\end{tabular}

* Significativo ao nível de $1 \%$ e $5 \%$ de acordo com o teste $\mathrm{F}$; ${ }^{\text {ns }}$ Não significativo ao nível de $5 \%$ de acordo com o teste $\mathrm{F}$ 
Observa-se nas Figuras 1 e 2, que o número de frutos comerciais e número de frutos totais por planta teve efeito significativo com o aumento dos níveis de salinidade da água de irrigação, obtendo um valor máximo de 1,29 e 1,68 frutos, para o nível 0,54 $\mathrm{dS} \mathrm{m}^{-1}$, respectivamente. $\mathrm{O}$ incremento unitário da salinidade acima do menor nível $\left(0,54 \mathrm{dS} \mathrm{m}^{-1}\right)$ proporcionou uma redução de $8,32 \%$ e $8,70 \%$, respectivamente, no número de frutos comerciais e totais por planta. Cuenca (1989), afirma que a salinidade elevada do solo durante o período de floração pode reduzir o número de frutos pegados. Esses valores concordam com Souza (2004), que trabalhando com meloeiro submetido a diferentes níveis de salinidade e adubação potássica, observou que o aumento de $1 \mathrm{dS} \mathrm{m}^{-1}$ na salinidade ocasiona decréscimo nas variáveis estudadas. $\mathrm{O}$ fato do aumento da salinidade ocasionar decréscimo no desenvolvimento da cultura pode estar relacionado, de acordo com Maia (2005), ao decréscimo nos teores de nitrogênio. O mesmo observou que quanto maior a salinidade, menores são os teores de nitrogênio encontrados nas folhas e frutos.

Os resultados confirmam o que Silva (2002) obteve ao analisar a cultivar Trusty que teve um decréscimo no número de frutos comerciais por planta com o aumento no nível de salinidade, porém não condiz com o obtido com a cultivar Gold Mine melão do tipo Amarelo que se mostrou com número de frutos comerciais por planta constate para os diversos níveis salinos, demonstrando que escolha da cultivar é um fator de grande importância para a implantação do plantio com uso de água salina na irrigação. Medeiros et al. (2008), que trabalhando com o híbrido 'Trusty' (Cantaloupe) e 'Orange Flesh' (Honey Dew) utilizando duas águas de irrigação com diferentes níveis de salinidade $\left(1,10 ; 2,50\right.$ e $\left.4,50 \mathrm{dS} \mathrm{m}^{-1}\right)$, encontrou reduções no número de frutos comerciais de $44,0 \%$ apenas para o nível salino $4,50 \mathrm{dS} \mathrm{m}^{-1}$.

Esses resultados diferem dos encontrados por Medeiros et al. (2008) quando avaliou o efeito de freqüências de água com três níveis de salinidade $(1,1$; 2,5 e 4,5 $\mathrm{dS} \mathrm{m}^{-1}$ ) e dois híbridos de melão (Trusty e Orange Flesh), onde observou que a massa médias dos frutos foi reduzida com a água salina. A diferença de comportamento quanto ao efeito da salinidade na massa média dos frutos entre os trabalhos pode ser justificada pelo comportamento diferente entre as cultivares em resposta à salinidade. Tem-se observado que a redução no rendimento do meloeiro, em resposta à salinidade, é devido à diminuição tanto do número como da massa média dos frutos, ou apenas pela diminuição do número, ou apenas pela diminuição da massa média (ALENCAR et al., 2003; DIAS et al., 2006).

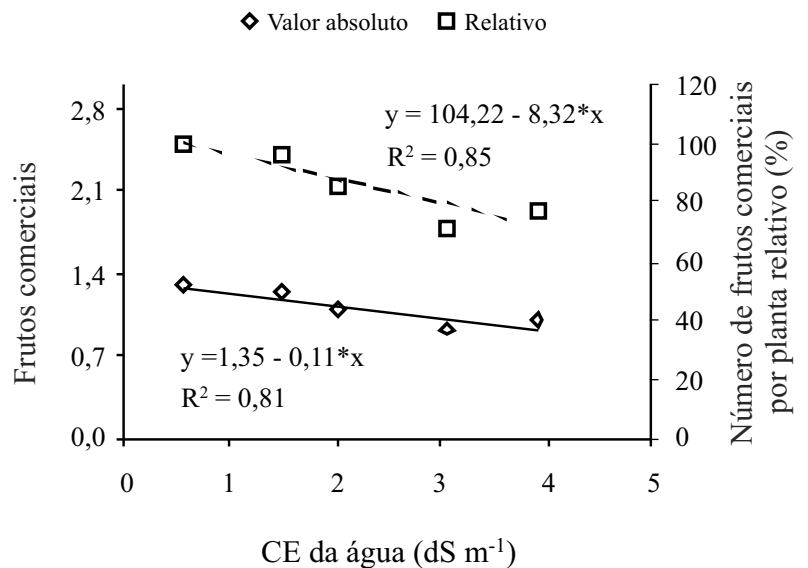

Figura 1 - Número de frutos comerciais por planta em função de diferentes níveis de salinidade. Mossoró/RN, UFERSA, 2009, ao nível 5\% de significância $(*)$

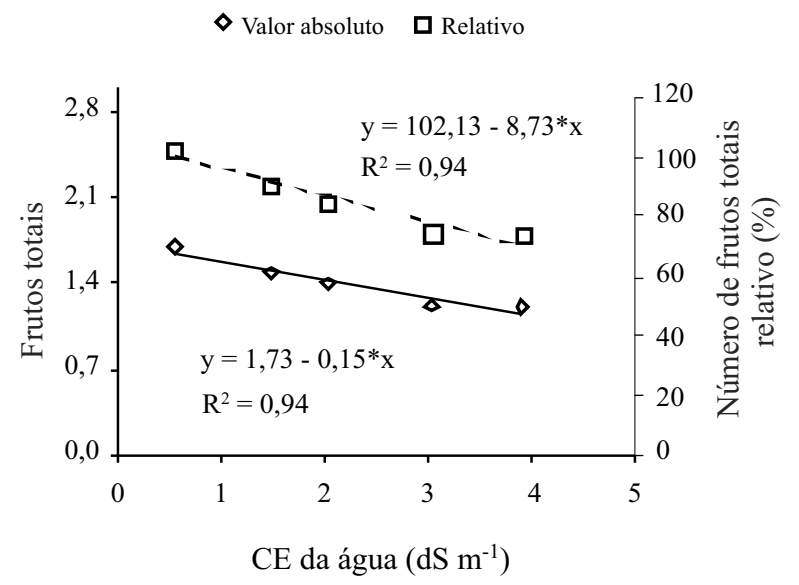

Figura 2 - Número de frutos totais por planta em função de diferentes níveis de salinidade. Mossoró/RN, UFERSA, 2009, ao nível 5\% de significância $(*)$

As produtividades comercial e total do melão foram influenciadas negativamente com o aumento dos níveis de salinidade, obtendo os maiores valores com o nível $0,54 \mathrm{dS} \mathrm{m}^{-1}$ de 48,62 $\mathrm{t} \mathrm{ha}^{-1}$ e 57,73 $\mathrm{t} \mathrm{ha}^{-1}$ (FIG. 3 e 4). O incremento unitário da salinidade acima do menor nível $\left(0,54 \mathrm{dS} \mathrm{m}^{-1}\right)$ proporcionou uma redução de $7,5 \%$ e $7,8 \%$, respectivamente, para a produção comercial e total. A principal causa da redução da produtividade de frutos foi diminuição no número de frutos comerciais por planta quando os níveis de sais na água ficaram elevados, já que a redução na massa não foi significativa. 


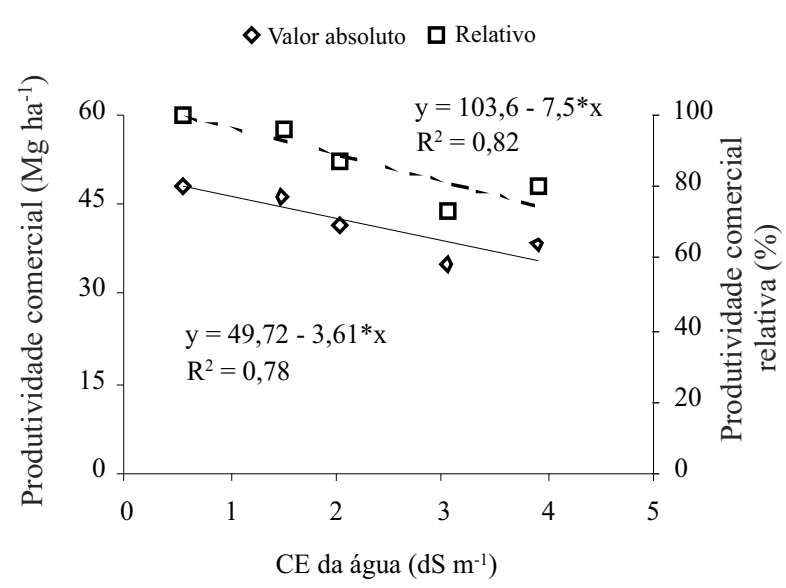

Figura 3 - Produtividade comercial (ton ha ${ }^{-1}$ ) em função de diferentes níveis de salinidade. Mossoró/RN, UFERSA, 2009, ao nível 5\% de significância (*)

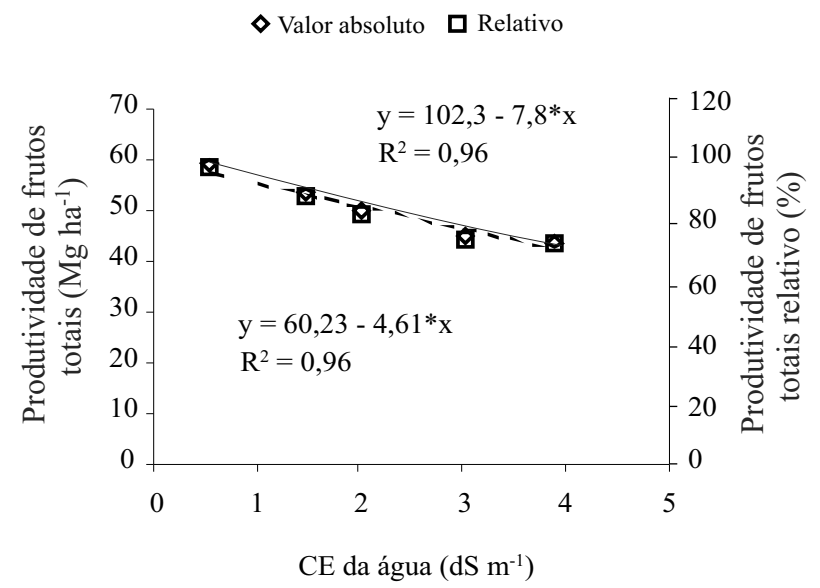

Figura 4 - Produtividade total (ton $\mathrm{ha}^{-1}$ ) em função de diferentes níveis de salinidade. Mossoró/RN, UFERSA, 2009, ao nível 5\% de significância $(*)$

Silva et al. (2005) obteve reduções de $15 \%$ e $36 \%$ nos níveis $2,5 \mathrm{dS} \mathrm{m}^{-1}$ e $4,4 \mathrm{dS} \mathrm{m}^{-1}$, respectivamente, quando comparado com a salinidade de $1,2 \mathrm{dS} \mathrm{m}^{-1}$. Também constatou que o número de frutos por planta foi o principal componente de produção responsável pela perda de rendimento. Resultados semelhantes foram encontrados por Souza Neto et al. (2003), trabalhando com os níveis de salinidade da água de irrigação de 0,$60 ; 1,90 ; 3,20$ e $4,50 \mathrm{dS} \mathrm{m}^{-1}$ e melão do tipo amarelo, o qual mostrou que salinidade de $4,50 \mathrm{dS} \mathrm{m}^{-1}$ ocasiona uma queda significativa na produtividade comercial do meloeiro.

\section{Conclusão}

O incremento da salinidade na água influencia negativamente o rendimento da cultura, com perdas relativas por incremento unitário de salinidade acima de $0,54 \mathrm{dS} \mathrm{m}^{-1}$, de $7,5 \% ; 7,8 \% ; 8,32 \%$ e $8,70 \%$, para produtividade comercial e total e número de frutos comerciais e totais, respectivamente, porém não foi afetado a massa média dos frutos.

\section{Agradecimentos}

Agradecemos o apoio financeiro do $\mathrm{CNPq}$ e a CoopyFrutas pelas cessões da área, água e outros tipos de apoio importantes para condução da cultura.

AFINEP/FAPERN/UFERSA/EMPARN/UFRNCTARN pela infraestrura e equipamentos necessários à pesquisa.

A CAPES/PROCAD-NF pelo apoio financeiro.

\section{Referências}

ALENCAR, R. D. et al. Crescimento de cultivares de melão amarelo irrigados com águas salinas. Revista Brasileira de Engenharia Agrícola e ambiental, v. 07, n. 02, p. 221-223, 2003.

CARMO FILHO, F. et al. Dados metereológicos de Mossoró. Mossoró: ESAM/FGD, 1991. 110 p. (Coleção Mossoroense, 630).

CRISÓSTOMO L. A. et al. Adubação, irrigação, híbridos e práticas culturais para o meloeiro no Nordeste. Fortaleza: Embrapa Agroindústria Tropical. 2002. 21p. (Circular Técnica 14).

CUENCA, R. H. Irrigation system design: an engineering approach. Englewood Cliffs: Prentice Hall, 1989. 552p.

DIAS, N. S.; GHEYI, H. R.; DUARTE, S. N. Prevenção, manejo e recuperação dos solos afetados por sais. Piracicaba, SP: USP; ESALQ, 2003. (Série Didática No 13).

DIAS, N. da S. et al. Salinidade e manejo da fertirrigação em ambiente protegido. II: Efeito sobre o rendimento do meloeiro. Irriga, v. 11, n. 06, p. 376-383, 2006.

EMBRAPA. Centro Nacional de Pesquisa de Solos (Rio de Janeiro, RJ). Sistema brasileiro de classificação de solos. Brasília: EMBRAPA, 1999, 412p.

FRANCOIS, L. E.; MAAS, E. V. Crop response and management on salt-affected soils. In: PESSARAKALI, M. (ed). Handbook of plant and crop stress. New York: Marcel Dekker, 1993. p.149-181. 
IBGE. Instituto Brasileiro de Geografia e Estatística. 2008. 6 de janeiro. Indicadores conjunturais: produção agrícola/ agricultura. Disponível em: <http://www.ibge.gov.br/>. Acesso em: 22 abr. 2009.

MAIA C. E. et al. Teores foliar de nutrientes em meloeiro irrigado com águas de diferentes salinidades. Revista Brasileira de Engenharia Agrícola e Ambiental, v. 09, (Suplemento) p. 292-295, 2005.

MEDEIROS, J. F. de; DIAS, N. da S.; BARROS, A. de. Manejo da irrigação e tolerância do meloeiro a salinidade da água de irrigação. Revista Brasileira Ciências Agrárias, v. 03, n. 03, p. 242-247, 2008 .

MEDEIROS, J. F. et al. Caracterização das águas subterrâneas usadas para irrigação na área produtora de melão da Chapada do Apodi. Revista Brasileira de Engenharia Agrícola e Ambiental, Campina Grande, v. 07, n. 03, p. 469-472, 2003.

MEDEIROS, J. F. et al. Crescimento do meloeiro cultivado sob diferentes níveis de salinidade, com e sem cobertura do solo. Revista Brasileira de Engenharia Agrícola e Ambiental, v. 11, n. 03, p. 248-255. 2007.

QUEIROGA, R. C. F. et al. Germinação e crescimento inicial de híbridos de meloeiro em função da salinidade. Horticultura Brasileira, v. 24, n. 01, p. 315-319, 2006.
RIBEIRO JÚNIOR, J. I. Análises estatísticas no SAEG. Viçosa: Universidade Federal de Viçosa, 2001. 301 p.

SILVA, M. M. C. et al. Produtividade de frutos do meloeiro sob diferentes níveis de salinidade da água de irrigação, com e sem cobertura do solo. Horticultura Brasileira, v. 23, n. 02, p. 202-205, 2005.

SILVA, M. C. de CASTRO. Crescimento, produtividade e qualidade de frutos do meloeiro sob diferentes níveis de salinidade da água de irrigação e cobertura do solo. 2002. 65 f. Dissertação (Mestrado em Fitotecnia) - Escola Superior de Agricultura de Mossoró: Mossoró, RN.

SIVITREPE, N.; SIVITREPE, H. O.; ERIS, A. The effect os $\mathrm{NaCl}$ priming on salt tolerance in melon seedling grown under saline conditions. Scientiae Horticulturae, v. 97, n. 03/04, p. 229-237, 2003.

SOUZA, A. E. C., Rendimento da produção do meloeiro submetido a diferentes níveis de água e adubação potássica, Revista Brasileira Engenharia Agrícola e Ambiental, v. 08, n. 01, p. 8-12. 2004.

SOUZA NETO, E. R. et al. Produção de melão irrigado com águas de diferentes níveis de salinidade nas diferentes fases da cultura. Revista Caatinga, v. 16, n. 01/02, p. 39-45, 2003. 